\title{
Additive renoprotective effects of aliskiren on angiotensin receptor blocker and calcium channel blocker treatments for type 2 diabetic patients with albuminuria
}

\author{
Masanori Abe ${ }^{1}$, Noriaki Maruyama ${ }^{1}$, Hiroko Suzuki ${ }^{1}$, Yuki Fujii ${ }^{1}$, Midori Ito ${ }^{1}$, Yoshinori Yoshida ${ }^{1}$, \\ Kazuyoshi Okada ${ }^{1}$ and Masayoshi Soma ${ }^{1,2}$
}

This open-label, randomized, parallel-controlled study investigated the effects of the direct renin inhibitor aliskiren on 64 hypertensive type 2 diabetic patients with chronic kidney disease (CKD) and stable glycemic control who were already being treated with fixed doses of antihypertensive agents over a 24-week period. These agents were $80 \mathrm{mg}$ of the angiotensin II receptor blocker (ARB) telmisartan and $5 \mathrm{mg}$ of the calcium channel blocker (CCB) amlodipine. Patients were randomly assigned to two groups: the aliskiren group, receiving $150 \mathrm{mg}$ per day aliskiren, which was increased to $300 \mathrm{mg}$ per day $(n=32)$, and the CCB group, which received an increased dose $(7.5 \mathrm{mg}$ per day) of amlodipine that was increased to $10 \mathrm{mg}$ per day $(n=32)$. Urinary albumin excretion and urinary levels of 8-hydroxy-2'-deoxyguanosine $(8-0 \mathrm{HdG})$ and liver-type fatty acidbinding protein (L-FABP) were investigated in each group. Mean systolic and diastolic blood pressure decreased significantly in both groups, but there was no significant difference between the two groups at the end of the study. Serum creatinine levels and estimated glomerular filtration rate did not differ significantly between the two groups, but percent changes of urinary albumin/creatinine ratios, 8-OHdG and L-FABP levels decreased significantly in the aliskiren group compared with the CCB group. Plasma aldosterone levels were significantly decreased in the aliskiren group, which correlated significantly with those of urinary 8-OHdG and L-FABP. Our results suggest that the addition of aliskiren to the maximal recommended dose of ARB and usual dose of amlodipine is more effective in reducing albuminuria and oxidant stress in hypertensive diabetic patients with CKD than increasing the dose of amlodipine. Hypertension Research (2012) 35, 874-881; doi:10.1038/hr.2012.45; published online 17 May 2012

Keywords: aldosterone; aliskiren; chronic kidney disease; diabetic nephropathy; oxidant stress

\section{INTRODUCTION}

The importance of strict blood pressure (BP) control in patients with chronic kidney disease (CKD) was emphasized by the Japanese Society of Hypertension, which recommends a target BP of $<130 / 80 \mathrm{~mm} \mathrm{Hg}$ for hypertensive patients with CKD. ${ }^{1}$ However, despite the high prevalence of hypertension in patients with $\mathrm{CKD}$ $(81.8 \%)$, only $65.9 \%$ receive antihypertensive therapy, and in those that do receive treatment, only $23.3 \%$ are able to control their BP. ${ }^{2}$

Reduction in proteinuria using suitable therapeutic interventions, such as the antihypertensive regimen renin-angiotensin-aldosterone system (RAAS) blockade, is associated with a slower decline in renal function compared with other forms of treatment, yet RAAS blockade with angiotensin-converting enzyme inhibitors or angiotensin II type-1 receptor blockers (ARBs) is currently considered the most effective pharmacological approach for renoprotection. ${ }^{3,4}$ These agents reduce proteinuria more effectively than other antihypertensive drugs, therefore RAAS inhibitors should be titrated to maximal recommended doses. ${ }^{1,5}$ However, it is difficult to control BP with monotherapy, especially in patients with CKD, thus highlighting the need for combination drug therapy. ${ }^{6}$ In Japan, adequate BP control is achieved in $<50 \%$ patients, and in even fewer with co-morbidities such as diabetes mellitus.?

The RAAS, a major regulator of $\mathrm{BP}$, is an important therapeutic target for antihypertensive therapy. ${ }^{8}$ Although angiotensin-converting enzyme inhibitors and ARBs are effective for both controlling BP and reducing proteinuria, these antihypertensives do not completely suppress the RAAS, leading to a reactive rise in plasma renin activity. The renin and (pro) renin receptor system has also been

${ }^{1}$ Division of Nephrology, Hypertension and Endocrinology, Department of Internal Medicine, Nihon University School of Medicine, Tokyo, Japan and ${ }^{2}$ Division of General Medicine, Department of Internal Medicine, Nihon University School of Medicine, Tokyo, Japan

Correspondence: Dr M Abe, Division of Nephrology, Hypertension and Endocrinology, Department of Internal Medicine, Nihon University School of Medicine, 30-1, Oyaguchi Kami-chou, Itabashi-ku, Tokyo 173-8610, Japan.

E-mail: abe.masanori@nihon-u.ac.jp

Received 9 January 2012; revised 21 February 2012; accepted 21 February 2012; published online 17 May 2012 
shown to have a role in the development and progression of CKD. ${ }^{9,10}$ As angiotensin-converting enzyme inhibitors and/or ARBs increase prorenin levels and plasma renin activity, inhibition of renin is a potential therapeutic target for CKD patients, especially those who have received RAAS inhibitors. ${ }^{9,10}$

Aliskiren is a newly developed, orally active direct renin inhibitor for the treatment of hypertension, ${ }^{11-14}$ which has been shown by Parving et al. ${ }^{15,16}$ to reduce albuminuria in hypertensive diabetic patients with nephropathy who had already been treated with the maximal recommended dose of ARB (losartan $100 \mathrm{mg}$ daily). These findings further suggest the clinical utility of the dual blockade of RAAS with aliskiren and ARB for the treatment of CKD. Although it has been reported that the addition of aliskiren to olmesartan, another ARB, decreases not only urinary protein excretion but also urinary liver-type fatty acid-binding protein (L-FABP) levels in nondiabetic CKD stage $1-2$ patients, ${ }^{17}$ the relationship between changes in these urinary markers and changes in plasma aldosterone and plasma renin activity levels are not well known, particularly in diabetic subjects with CKD. Therefore, the objective of this study was to determine the effects of additional aliskiren therapy or dose titration therapy of amlodipine in hypertensive diabetic patients with CKD, who were already being treated with the maximal recommended dose of $\mathrm{ARB}$ ( $80 \mathrm{mg}$ telmisartan) and the usual dose of calcium channel blocker (CCB; $5 \mathrm{mg}$ amlodipine), on BP control and renoprotection.

\section{METHODS}

\section{Subjects and study design}

Sixty-four patients were enrolled in the study. Enrollment criteria were as follows: (1) treatment with a daily ARB dose of $80 \mathrm{mg}$ telmisartan and a daily CCB dose of $5 \mathrm{mg}$ amlodipine for at least 8 weeks before the study; (2) type 2 diabetes with nephropathy under stable glycemic control, defined as a hemoglobin Alc (HbAlc) level $<7.0 \%$ after administration of oral antidiabetic agents or insulin injection therapy for 8 consecutive weeks; (3) albuminuria: urinary albumin/creatinine $(\mathrm{Cr})$ ratio $>30 \mathrm{mgg}^{-1}$ (average of two consecutive measurements recorded during the 8-week pre-treatment period); (4) estimated glomerular filtration rate (eGFR) levels $30-89 \mathrm{ml} \mathrm{min}^{-1}$ per $1.73 \mathrm{~m}^{2}$; (5) hypertension: systolic and diastolic BP $\geqslant 130 / 80 \mathrm{~mm} \mathrm{Hg}$ recorded while the patient was in a sitting position during at least two independent clinic visits.

Exclusion criteria were as follows: (1) age $<20$ years or $>80$ years; (2) more than second-degree hypertension $(\mathrm{BP}>160 / 100 \mathrm{~mm} \mathrm{Hg})^{1}$; (3) massive albuminuria: urinary albumin/Cr ratio $>2000 \mathrm{mgg}^{-1}$ (average of two consecutive measurements recorded during the 8-week pre-treatment period); (4) eGFR $\geqslant 90 \mathrm{mlmin}^{-1}$ per $1.73 \mathrm{~m}^{2}$ or $<30 \mathrm{ml} \mathrm{min}^{-1}$ per $1.73 \mathrm{~m}^{2}$; (5) severe heart failure, angina, myocardial infarction or stroke occurring within 6 months from the start of the trial; and (6) diabetes with unstable glycemic control, defined as a HbAlc level of $\geqslant 7.0 \%$ after administration of anti-diabetic agents for 8 consecutive weeks.

An overview of the study design is shown in Figure 1. An independent investigator, who did not treat and had no knowledge of the subjects, monitored randomized subject entry, and subjects were randomly split into two groups; assignment particulars were then immediately delivered to individual investigators. The randomization method was modified by dynamic balancing of the serum creatinine $(\mathrm{sCr})$, eGFR and urinary albumin/Cr ratio values recorded at the time of patient registration.

After initial evaluation, the aliskiren group $(n=32)$ received $150 \mathrm{mg}$ per day aliskiren, which was increased up to $300 \mathrm{mg}$ per day, while the CCB group $(n=32)$ received an additional $2.5 \mathrm{mg}$ per day amlodipine (giving a total daily dose of $7.5 \mathrm{mg}$ amlodipine), which was increased to $5 \mathrm{mg}$ per day (total daily dose of $10 \mathrm{mg}$ amlodipine) over a 24 -week period.

The study was conducted with outpatients at our institutions who fulfilled the criteria. The study protocol was approved by the local ethics committee

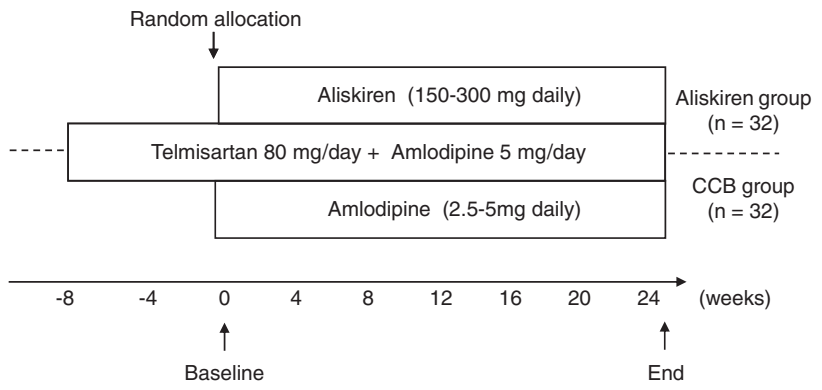

Figure 1 Study design.

and all patients gave their written informed consent for participation. The study was conducted in accordance with the Declaration of Helsinki.

\section{Intervention}

Doses of other anti-hypertensive agents and statins were maintained during the study. BP measurements were performed at the outpatient clinic according to the Japanese Society of Hypertension 2009 guidelines at fixed times after the administration of medications. ${ }^{1}$ The target BP was $<130 / 80 \mathrm{~mm} \mathrm{Hg}$. Measurements were made using a sphygmomanometer (Nippon Colin, Tokyo, Japan) and were performed twice with the patient in a sitting position after a 5-min rest. Patients were given dietary guidance, especially those under dietary restrictions.

\section{Biochemical and urinary assessments}

At each patient visit, safety variables and patient compliance with treatment regimens were assessed. Laboratory tests, including those for measuring $\mathrm{sCr}$, fasting plasma glucose, $\mathrm{HbAlc}$, hemoglobin $(\mathrm{Hb})$, aspartate aminotransferase, alanine aminotransferase, total cholesterol, low-density lipoprotein cholesterol, high-density lipoprotein cholesterol, triglyceride, sodium, potassium and uric acid levels, were performed using commercial kits employing routinely used clinical chemistry procedures. High-sensitivity C-reactive protein was measured by latex agglutination.

Urinary 8-hydroxy- $2^{\prime}$-deoxyguanosine $(8-\mathrm{OHdG})$ and L-FABP were measured at baseline before treatment and at week 24 by a specific enzyme linked immunosorbent assay (SRL, Tokyo, Japan) in the first morning urine sample, and values were expressed as a ratio to the urinary $\mathrm{Cr}$ concentration. Urinary albumin excretion was assessed by measuring urinary concentrations of albumin and $\mathrm{Cr}$ (albumin/Cr ratio) in the first morning urine sample. Urinary albumins were measured using the immunoturbidimetric assay. Plasma renin activity and aldosterone concentrations were measured by radioimmunoassay at a contract laboratory (SRL) at baseline and at the end of the study in the supine position after a 20-min rest. The eGFR was calculated using the following formula: ${ }^{18}$ eGFR $\left(\mathrm{ml} \mathrm{min}^{-1}\right.$ per $\left.1.73 \mathrm{~m}^{2}\right)=194 \times \mathrm{sCr}^{-1.094} \times \mathrm{age}^{-0.287}(\times 0.739$ for women $)$.

\section{Statistical analysis}

All values are expressed as mean \pm s.e.m. We used the unpaired $t$-test or Fisher's exact test to compare baseline characteristics of patients in the aliskiren and CCB groups. Differences between the two groups with regard to changes in systolic and diastolic BPs were evaluated by repeated-measures analysis of variance according to a general linear model. If the analysis of variance revealed a significant overall difference, a priori-defined pairwise comparisons were performed using the Student's $t$-test without adjustment for multiple tests. Intragroup changes in $\mathrm{s} C r$ values and the urinary albumin/ $\mathrm{Cr}$ ratio were analyzed using the paired $t$-test. The unpaired $t$-test was used to compare $\mathrm{sCr}$ values and the urinary albumin/Cr ratio between the aliskiren and $\mathrm{CCB}$ groups. Correlations were determined by the Spearman's rank correlation test. To identify independent determinants of albuminuria, urinary 8-OHdG and L-FABP, multiple stepwise regression analysis was performed. Statistical significance was set at $P<0.05$. 


\section{RESULTS}

\section{Baseline characteristics}

All enrolled patients $(n=64)$ remained in the study until the end of the trial. Baseline characteristics and initial medication are shown in Table 1. There were no significant differences between the two groups with regard to baseline characteristics.

\section{BP-lowering effect}

The final dose of aliskiren was $206 \pm 13 \mathrm{mg}$ per day in the aliskiren group, and that of amlodipine was $3.8 \pm 0.3 \mathrm{mg}$ per day (total daily dose, $8.8 \pm 0.3 \mathrm{mg}$ ) in the CCB group. Figure 2 shows the changes in systolic and diastolic BP. In both groups, systolic and diastolic BP values were significantly lower than baseline values after the initiation of additional therapy, but the values did not differ significantly between the two groups during the course of treatment. In the last month of treatment, no significant differences (NS) were observed between systolic BP (aliskiren group: $128 \pm 2 \mathrm{~mm} \mathrm{Hg}, \mathrm{CCB}$ group: $129 \pm 1 \mathrm{~mm} \mathrm{Hg}$ ) and diastolic BP (aliskiren group: $74 \pm 2 \mathrm{~mm} \mathrm{Hg}$, CCB group: $74 \pm 2 \mathrm{~mm} \mathrm{Hg}$ ) in the two groups.

The BP target value $(130 / 80 \mathrm{~mm} \mathrm{Hg})$ was achieved in 56 and $59 \%$ of all subjects in the aliskiren and CCB groups (NS), respectively. The heart rate showed no significant change between baseline and the end of the study in both groups, and there was no significant difference between the two groups at the end of the trial.

\section{Plasma renin activity and aldosterone levels}

As shown in Figure 3, plasma renin activity was significantly decreased in the aliskiren group after 24 weeks of treatment, and the difference at the end of the study between the two groups was significant (aliskiren group: $0.3 \pm 0.1 \mathrm{ng} \mathrm{ml}^{-1}$ per $\mathrm{h}$, CCB group: $2.7 \pm 0.5 \mathrm{ng} \mathrm{ml}^{-1}$ per h, $P<0.05$ ). Plasma aldosterone levels were also significantly decreased in the aliskiren group after 24 weeks of treatment, and the difference at the end of the study between the two groups was significant (aliskiren group: $68 \pm 6 \mathrm{pg} \mathrm{ml}^{-1}$, CCB group: $\left.101 \pm 8 \mathrm{pg} \mathrm{ml}^{-1}, P<0.01\right)$. However, no significant effects were observed in the CCB group.

\section{Anti-albuminuric effects}

Figure 4 shows that neither sCr levels nor eGFR levels differed significantly between the two groups at the end of the study (aliskiren group sCr: $1.2 \pm 0.1 \mathrm{mg} \mathrm{dl}^{-1}$, CCB group sCr: $1.1 \pm 0.1 \mathrm{mg} \mathrm{dl}^{-1}$, NS; aliskiren group eGFR: $47 \pm 2 \mathrm{ml} \mathrm{min}^{-1}$ per $1.73 \mathrm{~m}^{2}$, CCB group eGFR: $48 \pm 2 \mathrm{ml} \mathrm{min}^{-1}$ per $1.73 \mathrm{~m}^{2}$, NS).

As shown in Figure 5, the urinary albumin/Cr ratio was significantly decreased in the aliskiren group (from $577 \pm 88$ to $\left.352 \pm 57 \mathrm{mg} \mathrm{g}^{-1} \mathrm{Cr}, P<0.0001\right)$, but there was no significant change in the urinary albumin/Cr ratio in the CCB group. Furthermore, the percent changes from the baseline value of the urinary albumin/Cr ratio recorded for the aliskiren group were significantly lower compared with the CCB group (aliskiren group: $-40 \pm 4 \%$, CCB group: $-0.4 \pm 15 \%, P<0.01)$.

\section{Urinary 8-OHdG and L-FABP}

Urinary 8-OHdG levels significantly decreased from $15.5 \pm 1.8 \mathrm{ng} \mathrm{mg}^{-1} \mathrm{Cr}$ to $11.5 \pm 0.8 \mathrm{ng} \mathrm{mg}^{-1} \mathrm{Cr}$ after 24 weeks in the aliskiren group $(P<0.01$; Figure 6). Furthermore, there were significant differences in urinary $8-\mathrm{OHdG}$ levels between the two groups at the end of the study (aliskiren group: $11.5 \pm 0.8 \mathrm{ng} \mathrm{mg}^{-1}$ Cr; CCB group: $\left.14.6 \pm 1.2 \mathrm{ng} \mathrm{mg}^{-1} \mathrm{Cr}, P<0.05\right)$. Urinary L-FABP levels also significantly decreased from $20.7 \pm 3.0 \mathrm{ng} \mathrm{mg}^{-1} \mathrm{Cr}$ to $12.5 \pm 1.9 \mathrm{ng} \mathrm{mg}^{-1} \mathrm{Cr}$ after 24 weeks in the aliskiren group
Table 1 Patient baseline characteristics and medications

\begin{tabular}{|c|c|c|c|}
\hline Variables & Aliskiren group & $C C B$ group & P-value \\
\hline$N($ male/female $)$ & $32(17 / 15)$ & $32(18 / 14)$ & NS \\
\hline Age (years) & $67 \pm 2$ & $68 \pm 1$ & NS \\
\hline BMI $\left(\mathrm{kg} \mathrm{m}^{-2}\right)$ & $23.2 \pm 1.7$ & $22.9 \pm 1.6$ & NS \\
\hline Smoking (\%) & 28 & 28 & NS \\
\hline Dyslipidemia (\%) & 75 & 72 & NS \\
\hline Systolic BP (mm Hg) & $144 \pm 2$ & $143 \pm 1$ & NS \\
\hline Diastolic BP (mm Hg) & $83 \pm 2$ & $81 \pm 2$ & NS \\
\hline Heart rate (bpm) & $74 \pm 2$ & $74 \pm 2$ & NS \\
\hline Serum $\mathrm{Cr}\left(\mathrm{mg} \mathrm{dl}^{-1}\right)$ & $1.2 \pm 0.1$ & $1.1 \pm 0.1$ & NS \\
\hline eGFR $\left(\mathrm{ml} \mathrm{min}-1\right.$ per $\left.1.73 \mathrm{~m}^{2}\right)$ & $47 \pm 2$ & $48 \pm 2$ & NS \\
\hline Urinary albumin $/ \mathrm{Cr}$ ratio $\left(\mathrm{mgg}^{-1} \mathrm{Cr}\right)$ & $577 \pm 88$ & $562 \pm 95$ & NS \\
\hline
\end{tabular}

Medications ( $\mathrm{n}$ )

$\begin{array}{llll}\text { Antihypertensive agents } & & & \\ \quad \text { Thiazide diuretic } & 5 & 4 & \text { NS } \\ \text { Loop diuretic } & 4 & 4 & \text { NS } \\ \alpha \text {-Blocker } & 3 & 3 & \text { NS } \\ \beta \text {-Blocker } & 3 & 4 & \text { NS } \\ \text { ACE-inhibitor } & 2 & 1 & \text { NS } \\ \text { Antidiabetic agents } & & & \\ \quad \text { Glimepiride } & 7 & 6 & \text { NS } \\ \text { Metformin } & 3 & 2 & \text { NS } \\ \alpha \text {-Gls } & 4 & 4 & \text { NS } \\ \text { Pioglitazone } & 4 & 4 & \text { NS } \\ \text { Glinides } & 3 & 3 & \text { NS } \\ \text { DPP-4 inhibitors } & 8 & 10 & \text { NS } \\ \text { Insulin } & 9 & 8 & \text { NS } \\ \text { Statins } & 24 & 23 & \text { NS }\end{array}$

Abbreviations: $\alpha$-Gls, alpha-glucosidase inhibitors; ACE, angitensin-converting enzyme; $\mathrm{BMI}$, body mass index; BP, blood pressure; Cr, creatinine; DPP-4, dipeptidyl peptidase-4 eGFR, estimated glomerular filtration rate; NS, not significant.

$(P<0.001)$, and there were significant differences in these levels between the two groups at the end of the study (aliskiren group: $12.5 \pm 1.9 \mathrm{ng} \mathrm{mg}^{-1} \mathrm{Cr}$; amlodipine group: $19.9 \pm 2.8 \mathrm{ng} \mathrm{mg}^{-1} \mathrm{Cr}$, $P<0.05)$.

On the other hand, the CCB group showed little difference in urinary levels of 8 -OHdG and L-FABP during the study period (Figure 6). The percent changes from the baseline value of urinary 8-OHdG and L-FABP recorded for the aliskiren group were significantly lower than those of the CCB group (both $P<0.001$ ).

\section{Assessment of the factors related to albuminuria, urinary 8-OHdG and L-FABP levels}

As shown in Table 2, univariate analyses were performed to examine the relationships between changes in albuminuria, urinary $8-\mathrm{OHdG}$ and L-FABP levels and other variables in the aliskiren group. The change in albuminuria correlated with changes in fasting plasma glucose, HbA1c and low-density lipoprotein cholesterol. Multiple stepwise regression analysis found that only $\mathrm{HbAlc}$ was independently related to albuminuria. The change in urinary 8-OHdG correlated with changes in urinary L-FABP, high-density lipoprotein cholesterol and plasma aldosterone. Multivariate regression analysis showed that urinary L-FABP was a significant independent variable associated with changes in urinary $8-\mathrm{OHdG}$. Moreover, the change in 


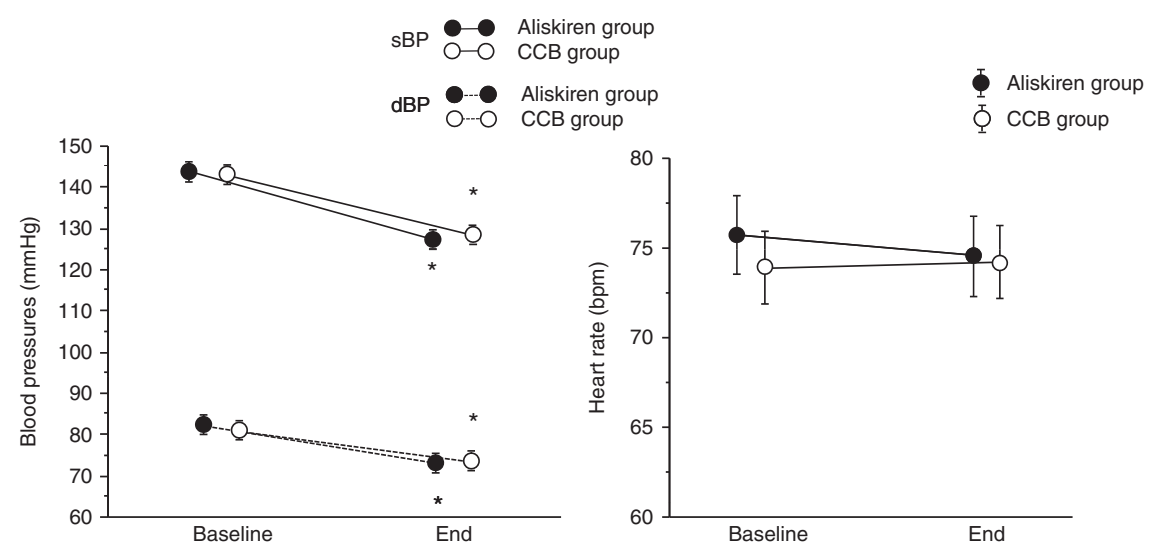

Figure 2 Changes in blood pressure and heart rate in the aliskiren group (solid circles) and calcium channel blocker (CCB) group (open circles) during the study period. ${ }^{*} P<0.0001$ vs. baseline. Abbreviarions: dBP, diastolic blood pressure; sBP, systolic blood pressure.

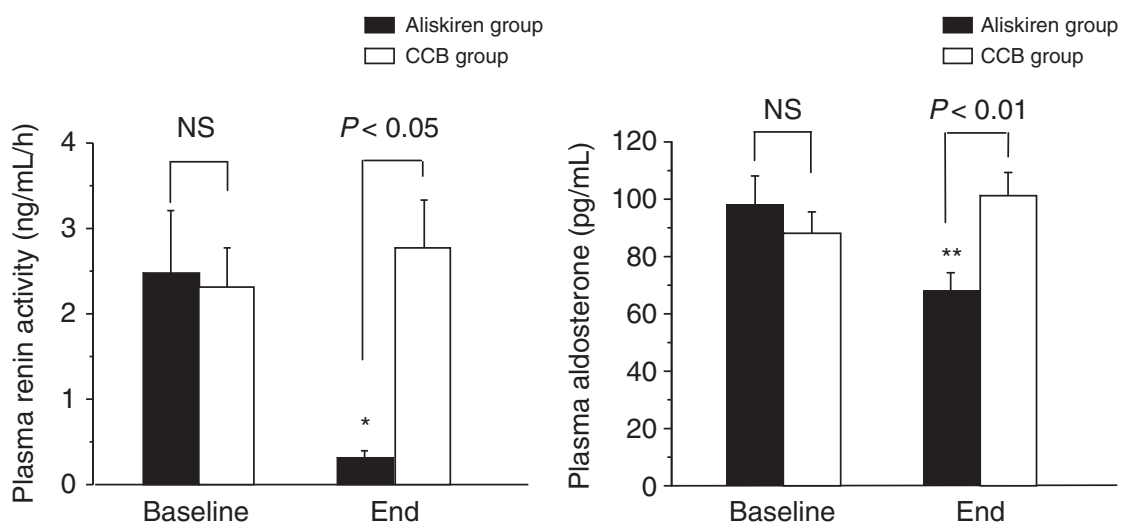

Figure 3 Changes in plasma renin activity and aldosterone levels between aliskiren group (solid bars) and calcium channel blocker (CCB) group (open bars). ${ }^{*} P<0.01,{ }^{* *} P<0.001$ vs. baseline.
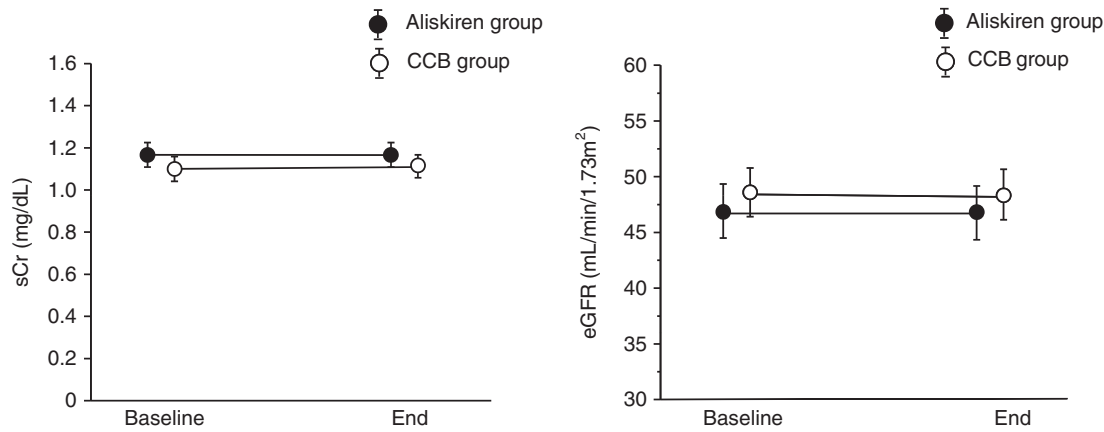

Figure 4 Changes in serum creatinine ( $\mathrm{s} C r$ ) levels and the estimated glomerular filtration rate (eGFR) between aliskiren group (solid circles) and calcium channel blocker (CCB) group (open circles).

L-FABP correlated with changes in urinary 8 -OHdG, plasma renin activity and plasma aldosterone. Multivariate regression analysis also showed that urinary $8-\mathrm{OHdG}$ and plasma aldosterone were significant independent variables associated with changes in urinary L-FABP.

Sub-analysis: subjects of the upper GFR and lower GFR group Subjects in the aliskiren group were subdivided into two groups based on eGFR median levels at baseline $\left(44.3 \mathrm{ml} \mathrm{min}^{-1}\right.$ per $\left.1.73 \mathrm{~m}^{2}\right)$ : the upper GFR group (eGFR, $\geqslant 44.3 \mathrm{ml} \mathrm{min}^{-1}$ per $1.73 \mathrm{~m}^{2}$ ) and the lower GFR group (eGFR, $<44.3 \mathrm{ml} \mathrm{min}^{-1}$ per $1.73 \mathrm{~m}^{2}$ ), and subgroup analysis was performed. In both the upper- and lower-GFR groups, there were no significant differences in age, dosage of aliskiren, percent changes in urinary albumin/Cr ratios, urinary 8-OHdG, L-FABP, plasma renin activity, glycemic indices or electrolytes. However, percent change of plasma aldosterone was greater in the lower GFR group compared with the upper GFR group. There was no significant difference in the change of systolic and diastolic BPs or eGFR (Table 3). 


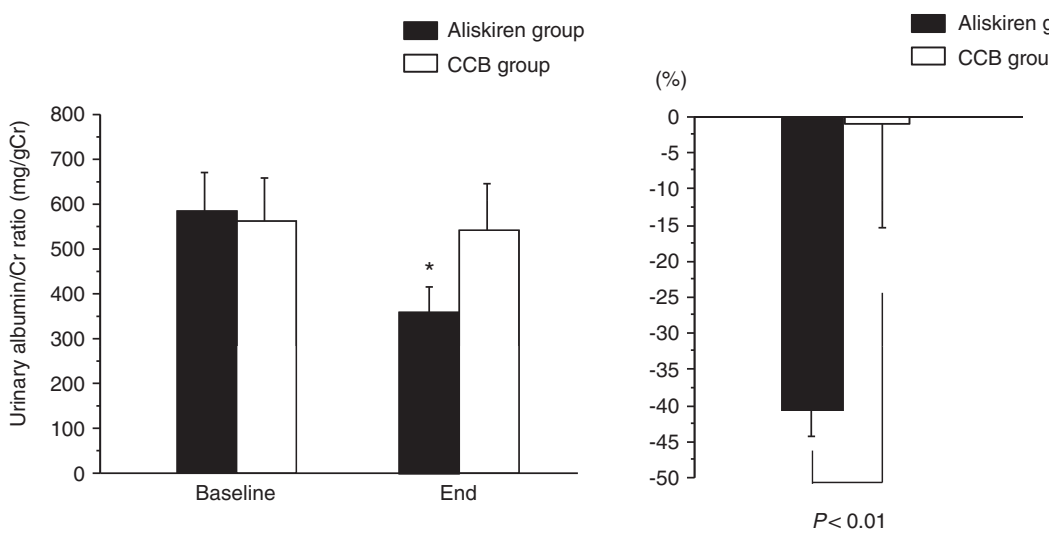

Figure 5 Changes in urinary albumin/creatinine $(\mathrm{Cr})$ ratio and the corresponding percent changes from baseline between aliskiren group (solid bars) and calcium channel blocker (CCB) group (open bars). ${ }^{*} P<0.0001$ vs. baseline.

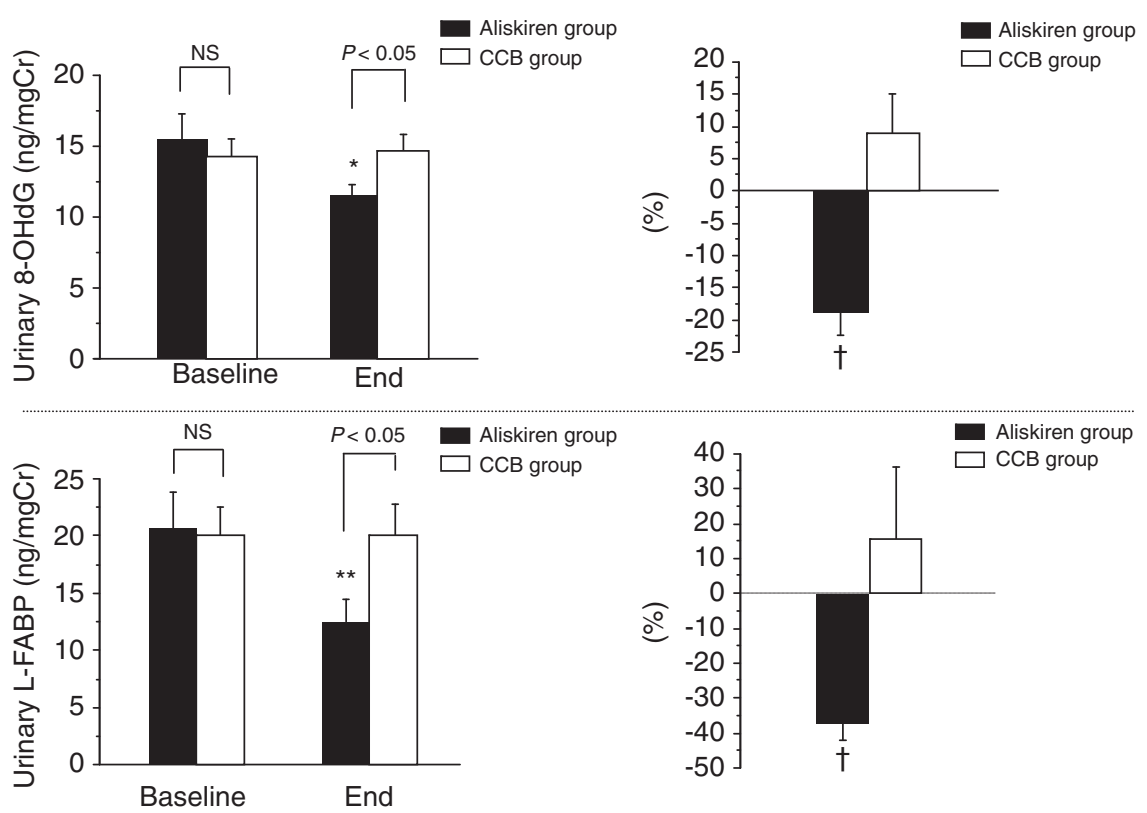

Figure 6 Changes in urinary 8-hydroxy-2'-deoxyguanosine (8-OHdG) and liver-type fatty acid-binding protein (L-FABP) levels between aliskiren group (solid bars) and calcium channel blocker (CCB) group (open bars). ${ }^{*} P<0.01,{ }^{* *} P<0.001$ vs baseline, ${ }^{\dagger} P<0.001$ vs. CCB group.

\section{Biochemical parameters}

As listed in Table 4, fasting plasma glucose levels and HbAlc levels did not differ significantly between the two groups during the study period. There were also no significant changes in total cholesterol, lowdensity lipoprotein cholesterol, high-density lipoprotein cholesterol, triglyceride, electrolyte or uric acid levels in either group. However, high-sensitivity C-reactive protein levels were significantly reduced in the aliskiren group.

\section{Adverse events}

During the observation period, transient increases in serum potassium levels $\left(>5.5 \mathrm{mmoll}^{-1}\right)$ were observed in four patients $(12.5 \%)$ in the aliskiren group and in two patients $(6.3 \%)$ in the CCB group, but this was not significantly different $(P=0.17)$. Furthermore, three of the four patients in the aliskiren group were also in the lower GFR group. No patients in either group exhibited increases in serum potassium levels of $>6.0 \mathrm{mmoll}^{-1}$. Although one patient in the aliskiren group had received calcium polystyrene sulfonate treatment, this was only short-lived, and serum potassium levels decreased to $<5.5 \mathrm{mmoll}^{-1}$ after 4 weeks of treatment. Potassium levels in other patients spontaneously decreased to $<5.5 \mathrm{mmoll}^{-1}$. No patients in either group exhibited a significant increase in the occurrence of adverse effects, such as hypotension, hyperglycemia, liver impairment, anemia or skin rash, and no patients required renal replacement therapy for hyperkalemia or progressive loss of renal function.

\section{DISCUSSION}

In the present study, we demonstrated that treatment with aliskiren in addition to the ARB telmisartan was more beneficial than an increase in the CCB amlodipine dose in diabetic patients with CKD. This was indicated by decreases in systolic and diastolic BP, albuminuria and urinary excretion levels of $8-\mathrm{OHdG}$ and L-FABP, which are clinical biomarkers of tubulointerstitial damage. 
Table 2 Univariate and stepwise multiple regression analysis for determinants of albuminuria, L-FABP and 8-OhdG in the aliskiren group

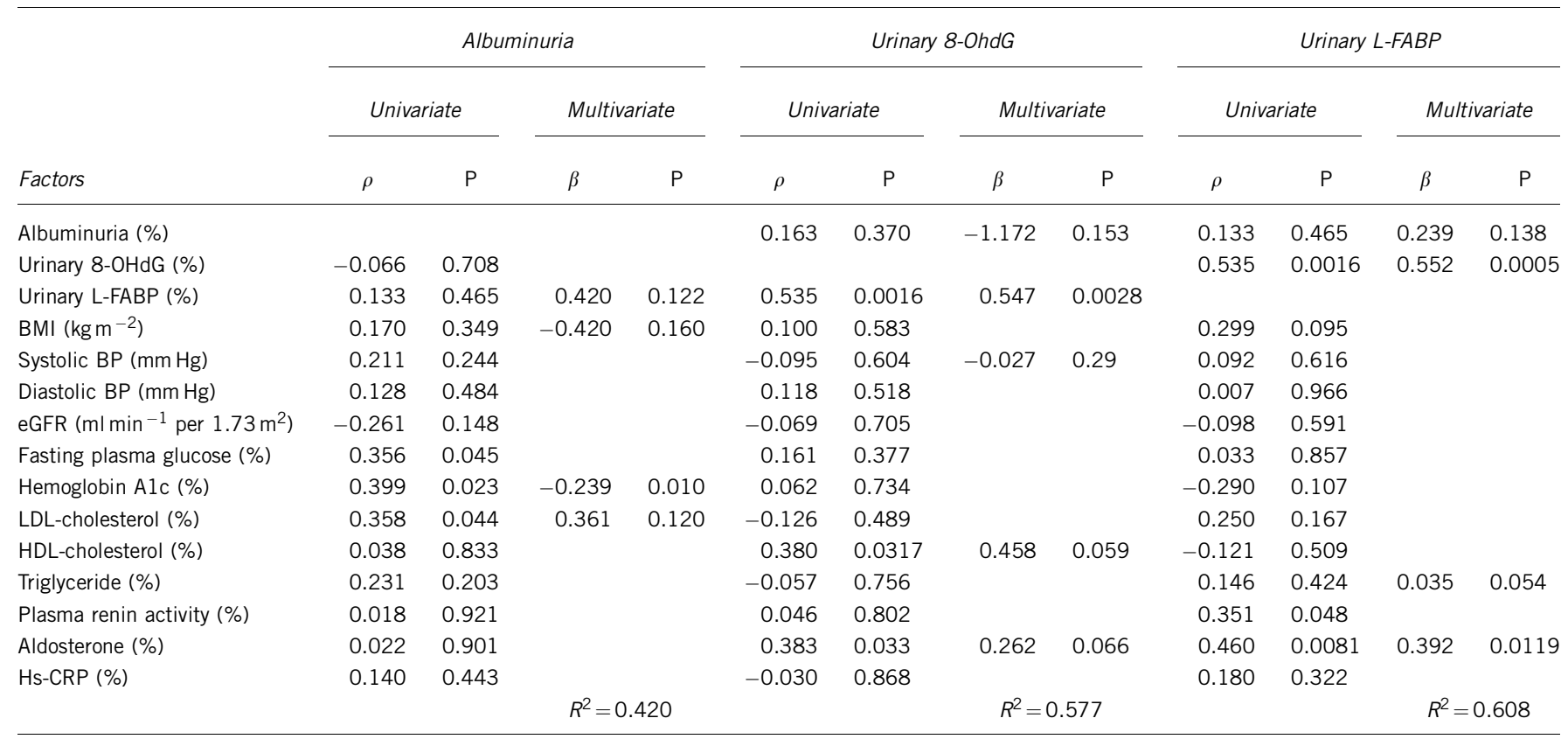

Abbreviations: BMI, body mass index; BP, blood pressure; eGFR, estimated glomerular filtration rate; HDL, high-density lipoprotein; Hs-CRP, high-sensitivity C-reactive protein; 8-OHdG, 8-hydroxy2'-deoxyguanosine; LDL, low-density lipoprotein; L-FABP, liver-type fatty acid-binding protein.

Table 3 Characteristics and changes in clinical variables according to baseline eGFR

\begin{tabular}{|c|c|c|c|}
\hline Variables & $\begin{array}{c}\text { Upper GFR } \\
\text { group }\end{array}$ & $\begin{array}{c}\text { Lower GFR } \\
\text { group }\end{array}$ & $\mathrm{P}$-value \\
\hline Mean eGFR $\left(\mathrm{ml} \mathrm{min}-1\right.$ per $\left.1.73 \mathrm{~m}^{2}\right)$ & $57 \pm 3$ & $35 \pm 1$ & \\
\hline$N$ (male/female) & $17(9 / 8)$ & $15(8 / 7)$ & NS \\
\hline Age (years) & $66 \pm 3$ & $71 \pm 3$ & NS \\
\hline Dosage of aliskiren (mg per day) & $194 \pm 17$ & $220 \pm 20$ & NS \\
\hline Systolic BP (mm Hg) & $-16 \pm 2$ & $-13 \pm 2$ & NS \\
\hline Diastolic BP (mm Hg) & $-9 \pm 1$ & $-6 \pm 2$ & NS \\
\hline Urinary albumin/Cr ratio (\%) & $-45 \pm 5$ & $-34 \pm 4$ & NS \\
\hline Urinary L-FABP (\%) & $-24 \pm 8$ & $-38 \pm 6$ & NS \\
\hline Urinary 8-OHdG (\%) & $-15 \pm 6$ & $-18 \pm 2$ & NS \\
\hline eGFR $\left(\mathrm{ml} \mathrm{min}{ }^{-1}\right.$ per $\left.1.73 \mathrm{~m}^{2}\right)$ & $0.6 \pm 0.9$ & $0.1 \pm 0.7$ & NS \\
\hline Plasma renin activity (\%) & $-70 \pm 6$ & $-77 \pm 4$ & NS \\
\hline Plasma aldosterone (\%) & $-13 \pm 8$ & $-32 \pm 6$ & 0.035 \\
\hline Hs-CRP (\%) & $-43 \pm 6$ & $-32 \pm 8$ & NS \\
\hline Fasting plasma glucose (\%) & $-3 \pm 2$ & $3 \pm 5$ & NS \\
\hline Percent changes of $\mathrm{HbA} 1 \mathrm{c}(\%)$ & $0.01 \pm 0.04$ & $-0.10 \pm 0.05$ & NS \\
\hline Sodium (\%) & $0.2 \pm 0.3$ & $0.6 \pm 0.3$ & NS \\
\hline Potassium (\%) & $1.4 \pm 1.9$ & $1.5 \pm 3.3$ & NS \\
\hline Uric acid (\%) & $-1.9 \pm 1.5$ & $-0.5 \pm 3.2$ & NS \\
\hline
\end{tabular}

Abbreviations: BP, blood pressure; $\mathrm{Cr}$, creatinine; eGFR, estimated glomerular filtration rate; $\mathrm{HbAlc}$, hemoglobin Alc; Hs-CRP, high-sensitivity C-reactive protein; 8-OHdG, 8-hydroxy-2' deoxyguanosine; L-FABP, liver-type fatty acid-binding protein.

Beyond its antihypertensive effects, recent data suggest that aliskiren may have beneficial effects on renal function by slowing the decline in GFR and reducing albuminuria, which are independent of its BP-lowering effects. ${ }^{15}$ In the AVOID study, those hypertensive patients with type 2 diabetes and nephropathy who received aliskiren and losartan combination therapy for 6 months showed a smaller decline in GFR than patients treated with placebo plus losartan, even though the BP was similar and well controlled in both treatment groups. ${ }^{15}$ In the aliskiren plus losartan group, $25 \%$ of patients experienced a reduction in the urinary albumin/Cr ratio of $>50 \%$ compared with only $12.5 \%$ patients in the placebo plus losartan group. Additional research has shown that the RAAS blockade with direct renin inhibition can also decrease albuminuria. In a study by Persson et al. ${ }^{19}$ a daily dose of $300 \mathrm{mg}$ aliskiren for 28 days was associated with a $44 \%$ decrease in the urinary albumin/Cr ratio and a reduction in 24-h systolic BP (after 7 days) in patients with type 2 diabetes and albuminuria. In the present study, although the BP lowering degree of aliskiren was similar to that of amlodipine, the reduction of albuminuria in the aliskiren group was greater than in the $\mathrm{CCB}$ group, suggesting that aliskiren may have beneficial pleiotropic actions in diabetic patients with CKD who have already been treated with the maximal recommended dose of ARB and usual dose of CCB.

In patients with diabetic nephropathy, the development of progressive diabetic kidney disease is associated with changes in proximal tubuli, and renal function and prognosis show a higher correlation with structural lesions in the tubulointerstitium than with glomerular changes. ${ }^{20}$ Inflammation and increased oxidative stress induced by hyperglycemia may contribute to the pathogenesis of diabetic complications including nephropathy. ${ }^{21,22}$ When advanced glycation end-products, shear stresses and angiotensin II stimulate their respective receptors, nicotinamide adenine dinucleotide phosphate oxidase activity is enhanced and production of oxidative stress is increased. ${ }^{21,23}$ Urinary L-FABP is an important marker of tubulointerstitial changes in diabetic nephropathy, while oxidative stress is a pathogenetic factor underlying diabetic complications such as nephropathy. ${ }^{24-27}$

Furthermore, diabetic hyperglycemia is associated with increased production of reactive oxygen species. ${ }^{22}$ Reactive oxygen species damage to DNA necessitates the induction of various DNA repair 


\begin{tabular}{|c|c|c|c|c|c|c|}
\hline \multirow[b]{2}{*}{ Variables } & \multicolumn{3}{|c|}{ Aliskiren group } & \multicolumn{3}{|c|}{$C C B$ group } \\
\hline & Baseline & End & P-value & Baseline & End & P-value \\
\hline Fasting plasma glucose $\left(\mathrm{mg} \mathrm{dl}^{-1}\right)$ & $130 \pm 5$ & $127 \pm 5$ & 0.50 & $123 \pm 4$ & $126 \pm 4$ & 0.27 \\
\hline Hemoglobin A1c (\%) & $6.5 \pm 0.1$ & $6.5 \pm 0.1$ & 0.30 & $6.4 \pm 0.1$ & $6.4 \pm 0.1$ & 0.52 \\
\hline Total cholesterol (mg dl-1) & $168 \pm 6$ & $166 \pm 6$ & 0.19 & $177 \pm 4$ & $175 \pm 4$ & 0.72 \\
\hline LDL-cholesterol (mg dl-1) & $87 \pm 5$ & $83 \pm 5$ & 0.06 & $86 \pm 3$ & $85 \pm 3$ & 0.40 \\
\hline HDL-cholesterol (mg dl-1) & $53 \pm 2$ & $51 \pm 2$ & 0.16 & $57 \pm 3$ & $56 \pm 3$ & 0.29 \\
\hline Triglyceride $\left(\mathrm{mg} \mathrm{dl}^{-1}\right)$ & $117 \pm 7$ & $109 \pm 7$ & 0.45 & $135 \pm 7$ & $129 \pm 8$ & 0.56 \\
\hline Sodium $\left(\mathrm{mmoll}^{-1}\right)$ & $140 \pm 0.3$ & $141 \pm 0.3$ & 0.08 & $141 \pm 0.4$ & $142 \pm 0.4$ & 0.07 \\
\hline Potassium (mmoll-1) & $4.4 \pm 0.1$ & $4.4 \pm 0.1$ & 0.63 & $4.4 \pm 0.1$ & $4.4 \pm 0.1$ & 0.95 \\
\hline Uric acid $\left(\mathrm{mgdl}^{-1}\right)$ & $6.5 \pm 0.3$ & $6.5 \pm 0.3$ & 0.55 & $6.3 \pm 0.2$ & $6.4 \pm 0.2$ & 0.21 \\
\hline High-sensitivity CRP $\left(\mathrm{mgl}^{-1}\right)$ & $0.67 \pm 0.08$ & $0.45 \pm 0.08$ & 0.0012 & $0.55 \pm 0.07$ & $0.62 \pm 0.10$ & 0.24 \\
\hline
\end{tabular}

Abbreviations: CCB, calcium channel blocker; CRP, C-reactive protein; HDL, high-density lipoprotein; LDL, low-density lipoprotein.

processes, which can result in the urinary excretion of products such as 8 -OHdG. ${ }^{28}$ Increased urinary 8 -OHdG and the risk of vascular complications may be present at early stages of diabetes. ${ }^{29}$ For this reason, urinary $8-\mathrm{OHdG}$ is a sensitive biomarker of oxidative DNA damage, and is also significantly correlated with the severity of tubulointerstitial lesions. ${ }^{30}$ In the present study, we showed that aliskiren is more effective than amlodipine in protecting against tubulointerstitial injury and in reducing oxidative stress in diabetic patients with CKD.

Accumulating experimental and clinical evidence continues to show that excess aldosterone not only promotes the retention of sodium and body fluid but also induces cardiac and renal injury causing cardiac hypertrophy, glomerulosclerosis, renal inflammation and fibrosis. ${ }^{31-33}$ Moreover, aldosterone induces oxidative stress in vascular cells through nicotinamide adenine dinucleotide phosphate oxidase activation, which has a central role in endothelial dysfunction and atherosclerotic vascular disease. ${ }^{34-36}$ Therefore, targeting aldosterone synthesis and release may be clinically important in preventing cardiovascular disease. Our findings show a significant correlation between changes in serum aldosterone levels and changes in urinary 8-OHdG and L-FABP levels. Furthermore, the independent correlation between serum aldosterone and urinary L-FABP levels suggests that the aliskiren-induced decrease in urinary L-FABP is caused in part by the reduced serum aldosterone levels. Although aliskiren treatment decreased not only the urinary albumin/Cr ratio, but also the urinary 8-OHdG and/or L-FABP levels, no relationship was evident between changes in albuminuria and urinary $8-\mathrm{OHdG}$ or L-FABP. Therefore, aliskiren might act independently on the glomeruli and the tubulointerstitium. Further investigations are needed to clarify whether aliskiren can indeed improve tubulointerstitial damage through the inhibition of aldosterone synthesis and subsequent oxidative stress, and whether these effects prevent the progression of renal dysfunction in diabetic patients with CKD.

The AVOID study showed that renal dysfunction, serum $\mathrm{Cr}$ elevation $>2.0 \mathrm{mg} \mathrm{dl}^{-1}$ and serum potassium elevations $>5.5 \mathrm{mmoll}^{-1}$ were more frequent in the aliskiren group compared with the placebo group in diabetic patients with eGFR of $<60 \mathrm{ml} \mathrm{min}^{-1}$ per $1.73 \mathrm{~m}^{2} .{ }^{37,38}$ Furthermore, the ALTITUDE study observed an increased incidence of nonfatal stroke, renal complications, hyperkalemia and hypotension in diabetic patients with CKD after 18-24 months of treatment. ${ }^{39,40}$ In the present study, hyperkalemia was found in four patients in the aliskiren group, who were also mostly in the lower GFR group. However, the mean dosage of aliskiren in our subjects was relatively low ( $206 \mathrm{mg}$ daily) compared with that in many other reports $(300 \mathrm{mg}$ daily). Therefore, the frequency of adverse events such as hyperkalemia and loss of renal function might be less in our study. Nevertheless, monitoring of renal function and electrolytes during aliskiren therapy should be considered for all patients with moderate to severe renal dysfunction.

Our study design suffered from the limitations of small sample size and short treatment duration. Moreover, changes in sCr levels were too small for adequate evaluation of the influence of aliskiren therapy. Additional long-term investigations are therefore necessary to accurately assess the renoprotective effects of aliskiren and ARB combination therapy in diabetic patients.

In conclusion, we show here that aliskiren treatment leads to a greater reduction of albuminuria, plasma aldosterone and urinary 8-OHdG and L-FABP levels than up-titration of amlodipine in diabetic patients with CKD. These aliskiren effects appear to make the drug more advantageous in terms of the progression of renal dysfunction and preventing cardiovascular tissue and organ injuries in such patients. We propose that aliskiren therapy should be considered as an additive therapeutic modality for hypertensive diabetic patients whose BP is not sufficiently controlled by RAASinhibition therapy with $\mathrm{ARB}$ or $\mathrm{CCB}$ and for the amelioration of tubulointerstitial injury.

\section{CONFLICT OF INTEREST}

The authors declare no conflict of interest.

1 Japanese Society of Hypertension. Japanese Society of Hypertension Guidelines for the Management of Hypertension (JSH 2009). Hypertension Res 2009; 32: 4-107.

2 Wong ND, Lopez VA, L'Italien GL, Chen R, Kline S, Franklin S. Inadequate control of hypertension in US adults with cardiovascular disease co morbidities in 2003-2004. Arch Int Med 2007; 167: 2431-2436.

3 Lewis EJ, Hunsicker LG, Bain RP, Rohde RD. The effect of angiotensin-convertingenzyme inhibition on diabetic nephropathy. The Collaborative Study Group. N Eng J Med 1993; 329: 1456-1462.

4 Brenner BM, Cooper MD, De Zeeuw D, Keane WF, Mitch WE, Parving HH et al. Effects of losartan on renal and cardiovascular outcomes in patients with type 2 diabetes and nephropathy. N Eng J Med 2001; 345: 861-869.

5 Lavermann GD, Henning RH, De Jong PE, Navis G, De Zeeuw D. Optimal antiproteinuric dose of losartan in nondiabetic patients with nephrotic range proteinuria. $A m \mathrm{~J}$ Kidney Dis 2001; 38: 1381-1384.

6 Waeber B. Managing hypertension in high-risk patients: lessons and promises from the STRATHE and ADVANCE trials. J Hypertens 2006; 24: 19-27. 
7 Mori H, Ukai H, Yamamoto H, Saitou S, Hirao K, Yamauchi M et al. Current status of antihypertensive prescription and associated blood pressure control in Japan. Hypertens Res 2006; 29: 143-151.

8 Ferrario C. Role of angiotensin II in cardiovascular disease-therapeutic implications of more than a century of research. J Renin Angiotensin Aldosterone Syst 2006; 7: 3-14.

9 Ichihara A, Kaneshiro Y, Takemitsu T, Sakoda M, Itoh H. The (pro)renin receptor and the kidney. Semin Nephrol 2007; 27: 524-528.

10 Balakumar $\mathrm{P}$, Jagadeesh G. Cardiovascular and renal pathologic implications of prorenin, renin, and the (pro)renin receptor: promising young players from the old renin-angiotensin-aldosterone system. J Cardiovasc Pharmacol 2010; 56: 570-579.

11 Riccioni G. Aliskiren in the treatment of hypertension and organ damage. Cardiovasc Ther 2011; 29: 77-87.

12 Azizi M, Webb R, Nussberger J, Hollenberg NK. Renin inhibition with aliskiren: where are we now, and where are we going? J Hypertens 2006; 24: 243-256.

13 Ito S, Nakura N, Breton SL, Keefe D. Efficacy and safety of aliskiren in Japanese hypertensive patients with renal dysfunction. Hypertens Res 2010; 33: 62-66.

14 Kushiro T, Itakura H, Abo Y, Gotou H, Terao S, Keefe DL. Aliskiren, a novel oral renin inhibitor, provides dose-dependent efficacy and placebo-like tolerability in Japanese patients with hypertension. Hypertens Res 2006; 29: 997-1005.

15 Persson $\mathrm{F}$, Lewis JB, Rossing P, Hollenberg NK, Parving HH. Aliskiren in combination with losartan reduces albuminuria independent of baseline blood pressure in patients with type 2 diabetes and nephropathy. Clin J Am Soc Nephrol 2011; 6: 1025-1031.

16 Parving HH, Persson F, Lewis JB, Lewis EJ, Hollenberg NKAVOID Study Investigators. Aliskiren combined with losartan in type-2 diabetes and nephropathy. $N$ Engl J Med 2008; 358: 2433-2446.

17 Nakamura T, Sato E, Amaha M, Kawagoe Y, Maeda S, Yamagishi S. Addition of aliskiren to olmesartan ameliorates tubular injury in chronic kidney disease patients partly by reducing proteinuria. J Renin Angiotensin Aldosterone Syst 2012; 13: 122-127.

18 Matsuo S, Imai E, Horio M, Yasuda Y, Tomita K, Nitta K et al. Revised equations for estimated GFR from serum creatinine in Japan. Am J Kidney Dis 2009; 53: 982-992.

19 Persson F, Rossing P, Reinhard H, Juhl T, Stehouwer CD, Schalkwijk C et al. Renal effects of aliskiren compared to and in combination with irbesartan in patients with type 2 diabetes, hypertension and albuminuria. Diabetes Care 2009; 32: 1873-1879.

20 Persson F, Rossing P, Schjoedt KJ, Juhl T, Tarnow L, Stehouwer CD et al. Time course of the antiproteinuric and abtihypertensive effects of direct renin inhibition in type 2 diabetes. Kidney Int 2008; 73: 1419-1425.

21 Thomas MC, Burns WC, Cooper ME. Tubular changes in early diabetic nephropathy. Adv Chronic Kid Dis 2005; 12: 177-186.

22 Brownlee M. Biochemistry and molecular cell biology of diabetic complications. Nature 2001; 414: 818-820.

23 Goodarzi MT, Navidi AA, Rezaei M, Rezaei HB. Oxidative damage to DNA and lipids: Correlation with protein glycation in patients with type 1 diabetes. J Clin Lab Anal 2010; 24: 71-76.

24 Sheetz MJ, King GL. Molecular understanding of hyperglycemia's adverse effects for diabetic complications. JAMA 2002; 288: 2579-2588.
25 Nakamura T, Sugaya T, Kawagoe Y, Ueda Y, Osada S, Koide H. Effect of pitavastatin on urinary liver-type fatty acid-binding protein levels in patients with early diabetic nephropathy. Diabetes Care 2005; 28: 2728-2732.

26 Abe M, Matuyama N, Okada K, Matsumoto S, Matsumoto K, Soma M. Effects of lipidlowering therapy with rosuvastatin on kidney function and oxidative stress in patients with diabetic nephropathy. J Atheroscler Thromb 2011; 18: 1018-1028.

27 Kamijo A, Kimura K, Sugaya T, Yamanouchi M, Hikawa A, Hirano N et al. Urinary fatty acid-binding protein as a new clinical marker of the progression of chronic renal disease. J Lab Clin Med 2004; 143: 23-30.

28 Kamijo A, Sugaya T, Hikawa A, Yamanouchi M, Hirata Y, Ishimitsu T et al. Clinical evaluation of urinary excretion of liver-type fatty acid-binding protein as a marker for monitoring of chronic kidney disease: a multicenter trial. J Lab Clin Med 2005; 145: 125-133.

29 Kasai H. Analysis of a form of oxidative DNA damage 8-hydroxy-2'-deoxyguanosine as a marker of cellular oxidative stress during carcinogenesis. Mutat Res 1997; 387: $146-163$.

30 Hata I, Kaji M, Hirano S, Shigematsu Y, Tsukahara H, Mayumi M. Urinary oxidative stress markers in young patients with type 1 diabetes. Pediatr Int 2006; 48: 58-61.

31 Kanauchi M, Nishioka $\mathrm{H}$, Hashimoto T. Oxidative DNA damage and tubulointerstitial injury in diabetic nephropathy. Nephron 2002; 91: 327-329.

32 Sun Y, Zhang J, Lu L, Chen SS, Quinn MT, Weber KT. Aldosterone-induced inflammation in the rat heart: role of oxidative stress. Am J Pathol 2002; 161: 1773-1781.

33 Struthers AD, MacDonald TM. Review of aldosterone- and angiotensin II induced target organ damage and prevention. Cardiovasc Res 2004; 61: 663-670.

34 Yoshida K, Kim-Mitsuyama S, Wake R, Izumi Y, Yukimura T, Ueda M et al. Excess aldosterone under normal salt diet induces cardiac hypertrophy and infiltration via oxidative stress. Hypertens Res 2005; 28: 447-455.

35 Shiffrin EL. Effects of aldosterone on the vasculature. Hypertension 2006; 47: 312-318.

36 Miyata K, Rahman M, Shokoji T, Nagai Y, Zhang GX, Sun GP et al. Aldosterone stimulates reactive oxygen species production through activation of NADPH oxidase in rat mesangial cells. J Am Soc Nephrol 2005; 16: 2906-2912.

37 Persson F, Lewis JB, Lewis EJ, Rossing P, Hollenberg NK, Parving $\mathrm{HH}$ et al. AVOID Study Investigators. Impact of baseline renal function on the efficacy and safety of aliskiren added to losartan in patients with type 2 diabetes and nephropathy. Diabetes Care 2010; 33: 2304-2309.

38 Harel Z, Gilbert C, Wald R, Bell C, Perl J, Juurlink D et al. The effect of combination treatment with aliskiren and blockers of the renin-angiotensin system on hyperkalaemia and acute kidney injury: systematic review and meta-analysis. $B M J$ 2012; 344: e42.

39 http://www.novartis.com/newsroom/media-releases/en/2011/1572562.shtml.

40 Parving HH, Brenner BM, McMurray JJ, de Zeeuw D, Haffner SM, Solomon SD et al. Aliskiren Trial in Type 2 Diabetes Using Cardio-Renal Endpoints (ALTITUDE): rationale and study design. Nephrol Dial Transplant 2009; 24: 1663-1671. 